\title{
A Entrega Consciente de Crianças para a Adoção Legal à Luz do Estatuto da Criança e do Adolescente ${ }^{1}$
}

Anna Gabriella Pinto da Costa ${ }^{2}$

\section{RESUMO}

Este trabalho visa a demonstrar que a entrega consciente de crianças para adoção revela-se como uma opção segura e acolhedora, cuja prática é capaz de diminuir os elevados índices de abandono de crianças no Estado do Ceará, além de fortalecer a adoção legal por meio do Cadastro Nacional de Adoção. Tal prática já era prevista superficialmente no Estatuto da Criança e do Adolescente, desde 2010, mas foi devidamente regulamentada pela Lei 13.509/17, promulgada em Novembro de 2017. No Estado do Ceará, por via do Projeto “Anjos da Adoção", parceria entre Tribunal de Justiça e Ministério Público do Estado do Ceará, a entrega consciente de crianças para adoção já acontece, fazendo com que as mães não sofram preconceito ou constrangimento com a escolha de entregar seus filhos para a adoção.

Palavras-chave: Entrega consciente. Adoção legal. Estatuto da Criança e do Adolescente. Lei 13.509/17.

\section{INTRODUÇÃO}

O abandono de crianças e a entrega de crianças por meio da adoção direta, ou intuito personae, são situações recorrentes no

1 Data de recebimento: 02/04/2018. Data de aceite: 18/06/2018.

2 Técnica Ministerial do Ministério Público do Estado do Ceará. Bacharel em Direito pela Universidade Christus. Email: anna.costa@mpce.mp.br 
Brasil. Trata-se de medidas extremas decorrentes de uma gravidez indesejada, seja pela ausência de educação sexual e do correto uso de métodos contraceptivos, seja pela falta de planejamento familiar ou, até mesmo, pelo não desenvolvimento dos laços afetivos entre mãe e filho.

Com o olhar voltado a essas mães e gestantes que desejam entregar seus filhos para adoção, o legislador, por meio da Lei no 13.509 , promulgada em 22 de Novembro de 2017, trouxe a regulamentação da entrega consciente.

Assim, diante da recente vigência da referida lei, foi produzido o presente trabalho, que tem como objetivo geral analisar a regulamentação trazida pelo referido diploma legal, sistematizar e debater o tema, contribuindo para discussão da matéria.

Para a realização do trabalho, foi utilizada como metodologia a pesquisa bibliográfica, constituída de livros e artigos, embora se trate de um tema recente e com poucas fontes, além de dados estatísticos oriundos do Ministério dos Direitos Humanos e do Tribunal de Justiça.

No primeiro capítulo, tratamos da adoção legal, apresentando sua evolução histórico-legislativa, trazendo à baila a adoção como espécie de família substituta, por intermédio do Cadastro Nacional de Adoção.

No segundo capítulo, foram trazidos dados e fatos relativos ao abandono e negligência de crianças no Brasil e no Estado do Ceará, demonstrando que há ligação direta entre a omissão do Estado em efetivar o direito à entrega consciente para adoção e os casos de abandono de crianças.

No terceiro capítulo, a Lei no 13.509/2017 foi o objeto do estudo, tendo sido feita uma breve análise da regulamentação da entrega consciente, procedimentos específicos e, ao final, trazemos o exemplo dessa entrega consciente por intermédio do Projeto "Anjos da adoção", desenvolvido pelo Ministério Público do Estado do Ceará e acolhido pelo Tribunal de Justiça do Estado do Ceará. Ao final, conclu- 
ímos sobre a importância da evolução legislativa na regulamentação da entrega consciente, e da necessidade de efetivação da mesma por meio de conscientização e mobilização da rede de atendimento, como forma de reduzir os casos de abandono de crianças.

\section{ADOÇÃO LEGAL}

Para que seja considerada legal, a adoção de uma criança ou adolescente deve ocorrer por via de um processo judicial, com a participação obrigatória do representante do Ministério Publico, somente podendo ser concedida por meio de uma sentença a pretendentes previamente habilitados, que participaram de avaliação e cursos preparatórios para a adoção.

A criança ou adolescente cujos pais foram destituídos do poder familiar, por omissão ou violação de direitos, é disponibilizado para adoção, cabendo ao Estado inseri-lo em uma família substituta responsável, com condições psicológicas e disponibilidade afetiva para recebê-lo.

Já a adoção intuito personae é a adoção feita mediante a entrega direta de crianças, na qual a mãe e/ou pai biológico entrega diretamente a criança para pais substitutos, sem o crivo do Poder Judiciário nem fiscalização do Ministério Público. Neste caso, não se pode garantir toda a proteção ao adotando, nem há respeito ao diploma legal, no que concerne à "fila da adoção", e ao combate do tráfico de crianças.

\subsection{Evolução legislativa do instituto da adoção}

Conceituando o instituto, o termo "adoção" vem do latim adoptione, que significa escolher, adotar. De acordo com Nucci (2014, p. 118), "a adoção é um ato voluntário e espontâneo, calcado no afeto e afinidade, que permite a aceitação de alguém como filho (a), para 
conceder-lhe toda a assistência material e moral [...]".

Com o advento da Constituição Federal, em 1988, em seu art. 227, surgiu a doutrina da proteção integral da criança e do adolescente, tendo como fundamento e interação o princípio da dignidade da pessoa humana. A referida doutrina defende que crianças e adolescentes são sujeitos de direitos, deixando de serem objetos passivos. Ademais, defende que é dever da sociedade, da família e do Estado garantir, com prioridade absoluta, a efetivação desses direitos. No que diz respeito à adoção, a Constituição passou a prever a não diferenciação entre filho adotivo e filho legítimo para fins de sucessão hereditária.

Nesse contexto constitucional, foi promulgado o Estatuto da Criança e do Adolescente - ECA, Lei n 8.069/90, normatizando a proteção integral da criança e do adolescente, regulamentando os procedimentos de adoção, destituição do poder familiar e medidas de proteção.

A Lei $n^{\circ}$ 12.010/2009, denominada Lei da Adoção, unificou os procedimentos relacionados à adoção, revogou os artigos do Código Civil relacionados à adoção, criou o cadastro nacional de adoção, aprimorou a sistemática da garantia do direito à convivência familiar, privilegiando-se a família natural e trouxe, expressamente, e pela primeira $v^{3} z^{3}$ a possibilidade de uma mãe ou gestante entregar seu filho à adoção, chamada entrega consciente, posteriormente regulamentada pela Lei $n^{\circ} 13.509 / 17$, última alteração significativa do ECA.

\subsection{Adoção como espécie de família substituta}

A Lei $n^{\circ}$ 12.010/2009 trouxe à baila os conceitos de família natural, família extensa e família substituta. A família natural é composta por identidade genética e consanguínea, na qual os ditos "laços de sangue" vinculam os indivíduos. A família extensa alcança os pa-

3 Art. 13, parágrafo único, ECA. 
rentes com os quais a criança ou o adolescente possui vínculos de afinidade e afetividade. E, por fim, a família substituta representa sucedâneo das anteriores quando estas se desfazem ou colocam a criança ou o adolescente em um ambiente de risco ou vulnerabilidade, considerando-se como espécies dessa modalidade a guarda, a tutela e a adoção (RIBEIRO, 2010).

Pela sistemática do Estatuto da Criança e do Adolescente, a adoção só ocorre quando esgotadas as tentativas de retorno familiar e manutenção de vínculo da criança ou adolescente à sua família natural ou extensa ${ }^{4}$, passando, assim, a ser uma medida excepcional.

A adoção deve ter o foco no adotando, visando o melhor interesse do menor:

A adoção, como hoje é entendida, não consiste em 'ter pena' de uma criança ou resolver situação de casais em conflito, ou remédio para a esterilidade, ou, ainda, conforto para a solidão. O que se pretende com a adoção é atender às reais necessidades da criança, dando-lhe uma família, onde ela se sinta acolhida, protegida, segura e amada. É bom que se reflita que existe um processo, um desafio permanente e necessidade de constante reflexão sobre o tema. [...] Para a corrente institucionalista, a adoção é um instituto de ordem pública, de profundo interesse do Estado, que teve origem na própria realidade social; não foi criada pela lei e sim regulamentada pelo direito positivo, em função da realidade existente. (GRANATO, 2012, p. 29-30).

Assim, a adoção representa uma modalidade de família substituta, com caráter excepcional e irrevogável, na qual é formado vinculo afetivo entre os pais adotivos e a criança ou adolescente adotando, sendo obrigatória a intervenção do Estado, mediante um processo judicial e uma série de procedimentos prévios e preparatórios, como a habilitação de pretendentes à adoção, e inserção de pretendentes habilitados e de crianças e adolescentes aptos à adoção em um sistema nacional e unificado chamado Cadastro Nacional de Adoção

4 Art. $39, \S 1^{\circ}, \mathrm{ECA}$. 
- CNA, salvo exceção prevista no art. 50, §13 do ECA.

Por outro lado, somente podem ser adotadas crianças e adolescentes que não tenham mais vínculo jurídico com seus pais biológicos, ou seja, somente serão aptos para adoção após os pais terem sido destituídos do poder familiar, mediante processo judicial, com direito ao contraditório e à ampla defesa.

Percebe-se, portanto, o rigor e cuidado que o legislador preconizou no instituto da adoção, priorizando-se a convivência familiar e, em último caso, permitindo-se a adoção segura e preparada por meio de um processo judicial, impedindo-se, assim, a adoção intuito personae ou direta.

Nesse contexto, a Lei $n^{\circ}$ 12.010/2009 previu em seu art. 13, parágrafo $\S 1^{\circ}$, que as gestantes ou mãe que manifestassem interesse em entregar seus filhos para adoção, fossem encaminhadas, sem constrangimento, à vara da infância e da juventude:

As gestantes que manifestam interesse em entregar seus filhos À adoção devem receber a devida orientação psicológica e também jurídica, de modo que a criança tenha identificada sua paternidade (nos moldes do previsto na Lei $n^{\circ}$ 8.560/92) e lhe sejam asseguradas condições de permanência junto à família de origem ou, se isto por qualquer razão não for possível, seja então encaminhada para adoção legal, junto a pessoas ou casais regularmente habilitados e cadastrados. (DIGIÁCOMO, 2017, p. 23-34).

Assim, o objetivo dessa previsão era coibir práticas criminosas, como a "adoção à brasileira", que está prevista no art. 242 do Código Penal, e adoções ilegais, como a adoção intuito personae.

\subsection{Adoção intuito personae e seus riscos}

Conforme já explanado, a adoção direta ou intuito personae ocorre quando os pais biológicos escolhem para quem entregar a criança em adoção, sem passar pelo sistema de justiça, sem preparação dos 
pais adotivos, sem a fiscalização do Ministério Público.

Este tipo de adoção não apenas é considerado ilegal, como possibilita o tráfico de crianças, coibido por força do art. 149-A, IV do Código Penal. Também não proporciona os direitos previstos ao adotando, dentre eles, o de conhecer sua origem biológica, tendo acesso irrestrito ao processo de adoção e ao de medidas protetivas, caso haja ${ }^{5}$.

A criança é inserida em um lar despreparado para a adoção, uma vez que não houve a avaliação psicológica e social dos pais adotivos, não se investigou a disponibilidade afetiva e as condições financeiras dos mesmos para acolher uma criança, aumentando-se o risco de devolução, ou abandono da mesma ao menor sinal de dificuldade na sua criação.

Também não há qualquer segurança para os adotantes, pois, pela ausência de processo de adoção e consentimento de entrega ratificado perante juiz e promotor de justiça, os pais biológicos ou família extensa podem desistir da entrega e reaver a criança, mesmo após a formação de vínculos afetivos.

São tantos os riscos e insegurança nessa prática, que o Ministério Público do Estado do Ceará, por meio do Centro de Apoio Operacional das Promotorias da Infância e da Juventude - CAOPIJ, criou o Projeto "CNA forte, Adoção segura"', com o objetivo de realizar audiências públicas nos municípios do Estado do Ceará (40 municípios, até maio de 2018), apresentando os riscos da adoção intuito personae e a segurança proporcionada pela adoção realizada pelo Poder Judiciário, por intermédio do Cadastro Nacional de Adoção - CNA.

5 Art. $47, \S 8^{\circ}$, ECA.

6 http://www.mpce.mp.br/caopij/projetos/projeto-cna-forte-adocao-segura/ 


\section{ABANDONO DE CRIANÇAS NO BRASIL E NO ESTADO DO CEARÁ}

Sabe-se que as mulheres foram criadas e educadas para serem mães, alegando-se a existência intrínseca de um instinto maternal, sendo o nascimento de uma criança a idealização de uma relação perfeita entre mãe e filho, na qual só existe amor e acolhimento.

Trata-se do mito do amor materno, ou seja, há a crença de que o amor materno seria instintivo e imaculado, inerente à mulher, quando, na verdade, é adquirido, influenciado pela evolução social e com conceitos modificados a depender do contexto histórico-cultural (BADINTER, 1985).

Diante dessa conjuntura, mães que não podiam, ou não queriam exercer a maternidade, antes que houvesse qualquer legislação que regulamentasse um fluxo de atendimento, e previsse normas a serem seguidas com relação à entrega de crianças para adoção, entregavam seus filhos na Roda dos Expostos, que teve sua implantação em 1726, em Salvador, vigorando até meados de 1950 em 13 (treze) Estados.

A Roda dos Expostos teve sua origem na idade média e tinha como objetivo de garantir o anonimato da mãe que desejasse entregar o filho, além de estimulá-la a levar a criança para a roda, e não abandoná-la no lixo, na porta da igreja ou de casas de família:

\footnotetext{
O nome da roda provem do dispositivo onde se colocavam os bebes que se queriam abandonar. Sua forma cilíndrica, dividida ao meio por uma divisória era fixada no muro ou na janela da instituição. No tabuleiro inferior e em sua abertura externa, o expositor depositava a criancinha que enjeitava. A seguir, ele girava a roda e a criança já estava do outro lado do muro. Puxava-se uma cordinha com uma sineta para avisar a vigilante ou rodeira que um bebe acabava de ser abandonado e o expositor furtivamente retirava-se do local, sem ser identificado. (MARCILIO, 2016, p. 55).
} 
A referida instituição cumpriu seu papel na história, tendo sido o único local que forneceu a devida assistência a crianças abandonadas no Brasil. Posteriormente, foram criados os abrigos e orfanatos, hoje denominados entidades de acolhimento institucional, devidamente fiscalizados pelo Poder Publico e Ministério Público, nas quais são acolhidas crianças e adolescentes, por intermédio do Conselho Tutelar, que estejam em situação de risco e vulnerabilidade.

Atualmente, embora existam as referidas entidades, ainda há muita desinformação e desarticulação, além do preconceito no que diz respeito à entrega de crianças para adoção na própria rede de garantia de direitos (Conselho Tutelar, Centro de Referência de Assistência Social - CRAS, Centro de Referência Especializado de Assistência Social - CREAS, etc).

Apenas no ano de 2017, o Estado do Ceará registrou, por via do Serviço Disque 100, mantido pela Secretaria dos Direitos Humanos ${ }^{7}$, mais de 300 (trezentos) casos de abandono e quase 1500 (mil e quinhentos) casos de negligência em amparo e responsabilização de crianças, além a ser a mãe da criança responsável pela violação de direitos em quase 2000 denúncias.

Esses dados só reforçam o fato de que o abandono começa na família, sendo indispensável a existência de medidas de apoio à família, através da rede socioassistencial, bem como da necessidade de disseminar a informação quanto à possibilidade da entrega consciente de crianças para adoção, que passa a ser uma alternativa para o abandono de crianças.

\section{ENTREGA CONSCIENTE PARA ADOÇÃO LEGAL}

A entrega de crianças para adoção sempre foi considerada um tabu, vestindo as mães, que não querem, ou não podem criar e edu-

7 Disponível em http://www.mdh.gov.br/informacao-ao-cidadao/ouvidoria/dados-disque-100/ balanco-geral-2011-a-2017-criancas-e-adolescentes.xls/view 
car seus filhos, de um estigma repleto de preconceito e julgamentos:

Não se pode confundir o ato de entrega voluntária de um filho para fins de adoção com o abandono. Infelizmente, estas mães, muitas vezes, acabam sendo vítimas de discriminação, de preconceitos, incompreensões, censuras, julgamentos morais e até de exclusão social. (KREUZ, 2012, p. 111).

Ademais, com a omissão legislativa sobre o tema, por tanto tempo, fez com que houvesse maior número de abandonos e entregas diretas de crianças a terceiros sem o crivo do Poder Judiciário.

Trata-se de direito da mulher, por optar não criar seu filho sem amor, sem vontade, sem condições psicológicas ou financeiras e direito da criança de estar inserido em um lar estruturado, com amor e tratamento digno.

\subsection{Regulamentações da entrega consciente: Lei no 13.509/17}

Foi dito, anteriormente, que não havia legislação que amparasse as mães que nutrissem a intenção de entregar seus filhos para a adoção, nem previsão de qualquer orientação na ocorrência de um caso concreto.

Neste sentido, oportuno mencionar o que defende Maria Antonieta Pisano Motta (2007, p. 245) sobre o tema:

A mãe que entrega ou pretende entregar seu filho em adoção quase não tem sido objeto de estudo em nosso meio, e muito menos de ações que visem à profilaxia dos danos que a entrega mal elaborada pode causar a mãe que entrega e especialmente à criança, sem mencionar as sequelas sociais de tal omissão. As necessidades da mãe biológica, seus motivos ou circunstancias, devidas aos aspectos psicológicos ou de outra ordem que influenciaram na entrega do filho em adoção, via de regra, são ignorados, muitas vezes desconhecidos mesmo, pois quase não Há quem faca perguntas esclarecedoras. Se a entrega do filho em adoção é o momento a partir do qual tudo começa, entendemos que este é um caminho a ser aberto, merecedor de aten- 
ção para que se alcance a compreensão das condições e necessidades dessas mães ignoradas pelo silêncio imposto à questão. (MOTTA, 2007, p. 245).

A partir da Lei $\mathrm{n}^{\circ} 12.010 / 09$, que acrescentou o parágrafo único ao artigo 13 do Estatuto da Criança e do Adolescente, prevendo que "as gestantes ou mães que manifestem interesse em entregar seus filhos para adoção serão obrigatoriamente encaminhadas à Justiça da Infância e da Juventude", que o cenário para essas mães passou a mudar.

Importa ressaltar que esse dispositivo foi alterado em 2016, pela Lei n' 13.257/16, incluindo a expressão "sem constrangimento", para deixar ainda mais claro que a mãe, gestante ou parturiente não deve sofrer qualquer preconceito, ou censura, por manifestar seu desejo de entregar o filho para a adoção.

Finalmente, em 2017, foi alterado o Estatuto da Criança e do Adolescente pela Lei $n^{\circ} 13.509 / 17$, que trouxe diversas inovações ${ }^{8}$, dentre elas a regulamentação da entrega consciente.

O artigo 19-A e seus parágrafos preveem um fluxo de atendimento e do procedimento a ser seguido, quando surgirem mães que tenham o interesse em entregar seus filhos para a adoção, sendo o próprio caput uma repetição do artigo 13, parágrafo único, citado anteriormente.

A gestante ou mãe, encaminhada à Vara da Infância e da Juventude, será ouvida por uma equipe interdisciplinar, que, posteriormente, apresentará relatório à autoridade judiciária\%. O objetivo dessa oitiva é identificar a motivação da entrega, informar as implicações decorrentes da entrega da criança, bem como identificar possível estado puerperal, razão pela qual se faz importante a boa qualificação e preparo da equipe que realizará a oitiva qualificada da mãe.

8 Regulamentação do apadrinhamento de crianças e adolescentes acolhidos, diminuição do prazo de avaliação periódica do acolhido, bem como do prazo máximo de acolhimento, participação dos grupos de apoio à adoção no procedimento de habilitação para adoção.

9 Art. 19-A, §10, ECA. 
Após a entrega do relatório, o juiz poderá determinar que a mãe ou gestante seja encaminhada para a rede de saúde e assistencial públicas ${ }^{10}$, ou seja, ao posto de saúde, para acompanhamento da gestação, do pré-natal e exames, bem como para o Centro de Referência Especializado de Assistência Social - CREAS e Conselho Tutelar, objetivando identificação do contexto familiar, e acompanhamento da gestação com o devido suporte socioassistencial. Os referidos encaminhamentos dependem da anuência da mãe ou gestante.

Há, ainda, previsão de busca pela família extensa, em prazo não superior a 90 (noventa) dias, podendo ser prorrogado por igual período ${ }^{11}$. Percebe-se que o Estatuto continua priorizando os laços de afinidade e afetividade que possam existir entre a criança e parentes correlatos.

Nesse ponto, há espaço para diversos questionamentos e debates: em se tratando de nascituro, deve-se buscar parentes com os quais a mãe gestante possui vínculos afetivos? A busca por parentes deve ser feita ainda que a mãe ou gestante requeira sigilo? Aqui, percebe-se o choque entre o direito da mãe ou gestante ao sigilo, e o direito da criança à convivência familiar.

A busca por parentes pode causar constrangimento e vitimização desta mãe, que já procura a Justiça com medo de ser responsabilizada pela decisão de entregar o filho para a adoção e fragilizada, uma vez que pode estar sofrendo rejeição da família ou do pai biológico. A persistência na busca de familiares pode ocasionar na desistência da entrega legal, ensejando uma adoção intuito personae ou, até mesmo o abandono após o nascimento:

A vontade da genitora deve ser respeitada, mesmo quanto ao sigilo, pois em muitos casos pode não desejar que o fato seja divulgado, inclusive em relação a outros familiares. Muitas vezes, observa-se, na prática, que as pessoas que deveriam ouvir e compreender a atitude da genitora, 
mobilizam-se, contatam vizinhos, parentes, etc., para convencer a genitora a cuidar do filho. O resultado, em muitos casos, é o abandono da criança dentro da própria família. (KREUZ, 2012, p. 111).

Por outro lado, a criança tem direito à convivência familiar, conforme o art. 19 do ECA, podendo existir situações em que a família se interesse em acolher a criança, quando questionada. Ademais, somente seria feita a busca por parentes com os quais haja vínculos de afinidade e afetividade com a mãe gestante ou criança.

Aqui, deve-se entender que o direito à convivência familiar pode ser exercido pela família natural, formada pelos pais e seus descendentes, pela família extensa, bem como pela família substituta, por meio da adoção, guarda ou tutela. Trata-se, na verdade, de um direito à convivência familiar afetiva, adotando-se o seu sentindo mais amplo, independente da sua origem (OLIVEIRA, 2011).

Não havendo indicação do genitor ou de algum representante da família extensa, que se disponibilize a adotar a criança, o juiz decretará a extinção do poder familiar, determinado que a mesma seja acolhida em entidade de acolhimento, ou permaneça sob a guarda provisória de pretendente Habilitado ${ }^{12}$. Caso contrário, será marcada audiência para ouvi-los e, caso não compareçam, a autoridade judiciária determinará a suspensão do poder familiar da mãe, encaminhando a criança para uma entidade de acolhimento, ou para família substituta, até que se finalize o processo ${ }^{13}$.

Em se tratando de gestante, após o nascimento da criança, a mãe será ouvida em audiência, acompanhada do pai indicado, se houver, para ratificar o interesse de entrega da criança para adoção, devendo ser orientada de todas as consequências e do caráter irrevogável da adoção ${ }^{14}$.

Por fim, caso haja desistência da entrega da criança para ado- 
ção, devidamente manifestada pelos genitores em audiência, ou por procedimento de entrevistas com a equipe interdisciplinar, a criança permanecerá com os genitores, que serão acompanhados pelo prazo de 180 (cento e oitenta) dias ${ }^{15}$. Este acompanhamento familiar é de suma importância, pois, deve-se averiguar a estabilidade emocional e psicológica dos pais, uma vez que já optaram pela desistência da criança. Busca-se evitar, ainda, a ocorrência de um possível tráfico de menores, abandono posterior, maus tratos e, até mesmo, adoção intuito personae.

\subsection{Projetos “Anjos da Adoção”}

Alguns Estados tiveram a iniciativa de criar uma regulamentação e desenvolver um fluxo de atendimento para as situações concretas do referido dispositivo, podendo-se citar os seguintes: Programa Mãe Legal ${ }^{16}$ em Recife-PE, o Programa de Acompanhamento de Gestantes $^{17}$ em Brasília-DF e o Projeto Anjos da Adoção em Fortaleza-CE.

O Tribunal de Justiça do Estado do Ceará, em parceria com a $2^{\text {a }}$ Promotoria de Justiça da Infância e da Juventude, implementou o Projeto "Anjos da Adoção", cujo objetivo é, mediante a criação de uma célula especializada no Departamento dos Agentes de Proteção, com profissionais das áreas da saúde ou ciências sociais, fiscalizar hospitais, maternidades e unidades de atendimento a crianças e gestantes.

O foco principal é o acolhimento e atendimento inicial das mães e parturientes que tenham manifestado o interesse em entregar

\footnotetext{
15 Art. 19-A, §80, ECA.

16 Programa criado e implementado no ano de 2011 pelo Dr. Élio Braz, Juiz de Direito da 2a Vara da Infância e da Juventude da Comarca de Recife, cujo objetivo é acolher mulheres gestantes ou parturientes que manifestam a intenção de entregar seu filho para adoção, oferecendo suporte através de uma equipe interdisciplinar e realizando os devidos acompanhamentos para a rede socioassistencial. 17 Iniciativa criada e desenvolvida em 2006, pelo Dr. Renato Rodovalho Scussel, Juiz de Direito da Vara da Infância e Juventude do Distrito Federal, cujo objetivo é realizar uma oitiva qualificada da mãe gestante, garantindo a ela um ambiente psíquico social para reflexão e construção da decisão de entregar o filho para a adoção ou não de uma de forma segura.
} 
o filho para adoção, evitando-se que as mesmas sofram qualquer constrangimento com tal manifestação de vontade ou, até mesmo, impedir a adoção a intuito personae, bem como acompanhar o fluxo de atendimento da mesma e proteção dos direitos da criança.

O projeto foi implementado oficialmente em 2017 e até março de 2018, os dados ${ }^{18}$ são os seguintes: 26 (vinte e seis) mães manifestaram a intenção de entregar seus filhos para adoção; 1 (uma) criança faleceu após o parto; 5 (cinco) mães desistido da entrega e 20 (vinte) crianças encontram-se aguardando a finalização do processo para serem disponibilizadas para adoção.

Antes mesmo da regulamentação da entrega consciente, por meio da Lei no 13.509/17, o Estado do Ceará já se deparava com essa realidade, com alta demanda, o que fez com que houvesse uma efetivação do direito de entrega consciente, de iniciativa do Ministério Público em parceria com o Poder Judiciário.

Entretanto, não se pode deixar de lado a obrigação do Estado e do Município em fortalecer a rede de atendimento, para que essas mães ou gestantes também sejam atendidas e acompanhadas por equipes capacitadas em postos de saúde, CRAS, CREAS e Conselho Tutelar.

\section{CONCLUSÃO}

O legislador brasileiro inovou ao apresentar uma regulamentação da entrega consciente, atendendo aos anseios e evolução da sociedade, observando-se os altos índices de abandono de crianças e ocorrências de adoções ilegais. Mas ainda não é o suficiente.

É preciso que sejam criados e efetivados fluxos de atendimento e acompanhamento dessas mães na rede socioassistencial, que os profissionais desta rede sejam capacitados, de forma que as mães ou

18 Informação verbal obtida pelo Dr. Dairton Costa de Oliveira, promotor de justiça da $2^{a}$ Promotoria de Justiça da Infância e da Juventude, responsável pelo acompanhamento e fiscalização do Projeto Anjos da Adoção. 
gestantes sejam acolhidas e amparadas, caso manifestem a intenção de entregar seus filhos à adoção, evitando-se que haja constrangimento, intermediação para a adoção intuito personae, ou o abandono posterior da criança.

O abandono de crianças e a adoção intuito personae persistem, devendo ser desmistificado que a entrega de crianças para adoção não representa crime, e que o processo de adoção não é burocrático ou lento, devendo-se demonstrar que o processo prioriza a segurança jurídica de todos.

O amparo às mães e gestantes pela legislação brasileira ainda é tímido, não se dando a verdadeira atenção e cuidado que elas merecem. Por já se encontrarem em um estado de completa vulnerabilidade, essas mães merecem total acolhimento por parte do Poder Judiciário, do Ministério Publico e da rede de garantia de direitos da criança e da juventude, sem quaisquer constrangimentos ou julgamentos, demonstrando que a entrega de um filho para a adoção não representa um ato de irresponsabilidade, e sim um verdadeiro ato de amor.

\section{THE CONSCIOUS PLACING CHILDREN FOR}

\section{LEGAL ADOPTION REGARDING THE CHILDREN AND ADOLESCENTS'S LEGISLATION}

\section{ABSTRACT}

This work demonstrates that the conscious placing children for adoption is a safe and welcoming option, whose practice is capable of reducing the high abandonment rates of children in the State of Ceará, as well as strengthening legal adoption through the National Registry of Adoption. This practice was already foreseen superficially in the Child and Adolescent's legislation since 2010, but was duly regulated by Law 13.509/17, promulgated in November 2017. In the State of Ceará, throu- 
gh the "Angels of Adoption's Project", partnership between Court of Justice and Public Ministry of the State of Ceará, conscious placing children already happens, making sure that mothers do not suffer prejudice or embarrassment with the choice to placing their children for adoption.

Keywords: Placing children legal adoption. Child and adolescent's legislation. Law 13.509/17.

\section{REFERÊNCIAS}

BADINTER, Elizabeth. Um Amor Conquistado: o mito do amor materno. Trad. Waltensir Dutra. Nova Fronteira: Rio de Janeiro, 1985. Disponível em: <http://www.redeblh.fiocruz.br/media/livrodigital\%20(pdf)\%20(rev).pdf> Acesso em 01 abr. 2018.

BECKER, Maria Josefina. Estatuto da Criança e do Adolescente Comentado: Comentários jurídicos e sociais. Coordenador Munir Cury. 7. ed. São Paulo: Malheiros, 2005.

BRASIL. Constituição da República Federativa do Brasil 1988. . Disponível em: <http://www.planalto.gov.br/ccivil_03/constituicao/ConstituicaoCompilado.htm>. Acesso em: 01 abr. 2018.

BRASIL. Estatuto da Criança e do Adolescente. Disponível em: <http:// www.planalto.gov.br/ccivil_03/leis/18069.htm>. Acesso em: 01 abr. 2018.

BRASIL. Lei Federal $\mathbf{n}^{\circ} \mathbf{1 3 . 5 0 9 / 2 0 1 7}$. Disponível em: <http://www.planalto.gov.br/ccivil_03/_ato2015-2018/2017/lei/L13509.htm>. Acesso em: 01 abr. 2018.

DIGIÁCOMO, Murillo José. Estatuto da criança e do adolescente anotado e interpretado. Curitiba: Ministério Público do Estado do Paraná. Centro de Apoio Operacional das Promotorias da Criança e do Adolescente, 2017. GRANATO, Eunice Ferreira Rodrigues. Adoção. Doutrina e prática. Com comentários a nova Lei da Adoção. Lei 12.010/09. 2. ed. Curitiba: Juruá, 2012.

KREUZ, Sérgio Luiz. Direito à Convivência familiar da criança e do adolescente: direitos fundamentais, princípios Constitucionais e alternativas ao acolhimento institucional. Curitiba: Juruá, 2012 
MARCÍLIO, Maria Luiza. A roda dos expostos e a criança abandonada na história do Brasil: 1 726-1950. In: História social da infância no Brasil. São Paulo: Cortez, 2016.

MOTTA, Maria Antonieta Pisano. Programa de atenção à gravidez não desejada: atenção à mulher que pretende entregar seu filho para adoção. Sapucaia do Sul: Notadez, 2007.

NUCCI, Guilherme de Sousa. Estatuto da Criança e do Adolescente comentado: em busca da Constituição Federal das crianças e dos adolescentes. Rio de Janeiro: Forense, 2014.

OLIVEIRA, Olivia Marcelo Pinto de. O parto anônimo à luz do constitucionalismo brasileiro. Curitiba: Juruá, 2011.

RIBEIRO, Paulo Hermano Soares. Nova lei de adoção comentada. Leme: Mizuno, 2010. 